\title{
First records and a new genus of comb-tailed spiders (Araneae: Hahniidae) from Thailand with comments on the six-eyed species of this family
}

\author{
Francisco Andrés RIVERA-QUIROZ ${ }^{1, *}$, Booppa PETCHARAD ${ }^{2} \&$ Jeremy A. MILLER $^{3}$ \\ ${ }^{1,3}$ Department of Terrestrial Zoology, Understanding Evolution group, \\ Naturalis Biodiversity Center, Darwinweg 2, 2333CR Leiden, The Netherlands. \\ ${ }^{1}$ Institute for Biology Leiden (IBL), Leiden University, Sylviusweg 72, \\ 2333BE Leiden, The Netherlands. \\ ${ }^{2}$ Faculty of Science and Technology, Thammasat University, Rangsit, Pathum Thani, 12121 Thailand. \\ *Corresponding author: andres.riveraquiroz@naturalis.nl \\ 2Email: ponksee.b@gmail.com \\ ${ }^{3}$ Email: jeremy.miller@naturalis.nl \\ ${ }^{1}$ urn:1sid:zoobank.org:author:970DAA18-987A-4819-BE46-A3D399F77409 \\ ${ }^{2}$ urn:lsid:zoobank.org:author:E1480A4E-3FA8-441C-A803-515B8AE7860D \\ ${ }^{3}$ urn:1sid:zoobank.org:author:3B8D159E-8574-4D10-8C2D-716487D5B4D8
}

\begin{abstract}
The family Hahniidae is reported from Thailand for the first time. The genus Hexamatia gen. nov. and two new species, Hexamatia seekhaow gen. et sp. nov. and Hahnia ngai sp. nov., are described and illustrated. DNA sequences are provided for all the species reported here. The phylogenetic position of the novel genus Hexamatia gen. nov. and its relation to Hahnia are discussed. Based on these results, a new combination is proposed for Hexamatia senaria (Zhang, Li \& Zheng, 2011) gen. et comb. nov. = Hahnia senaria . Known distribution of the species Hahnia saccata Zhang, Li \& Zheng, 2011, originally described from China, is expanded. A brief review and notes on the taxonomy of the six-eyed hahniids are included.
\end{abstract}

Keywords. Thai, Chiang Mai, new species, hahniids, phylogeny.

Rivera-Quiroz F.A., Petcharad B. \& Miller J.A. 2020. First records and a new genus of comb-tailed spiders (Araneae: Hahniidae) from Thailand with comments on the six-eyed species of this family. European Journal of Taxonomy 724: 51-69. https://doi.org/10.5852/ejt.2020.724.1157

\section{Introduction}

The family Hahniidae Bertkau, 1878 is relatively easy to identify due to the advanced location of the tracheal spiracle in relation to the spinnerets and the characteristic arrangement of these in more or less one transverse row (at least in the Hahniinae Bertkau, 1878) (Lehtinen 1967; Opell \& Beatty 1976). Other members of this family (e.g., Cicurina Menge 1871 and Cybaeolinae Lehtinen, 1967) do not share this transverse arrangement of the spinnerets (Roth 1967; Wang et al. 2019). The Hahniidae currently 
includes 351 species in 23 genera distributed worldwide (WSC 2020). The family status of Hahniidae has been confirmed by molecular phylogenies being placed within the RTA clade, closely related to Cybaeide Banks, 1892 and Dictynidae O. Pickard-Cambridge, 1871 (J.A. Miller et al. 2010; Wheeler et al. 2017). However, the relations and delimitations of its genera have always been problematic. Only a few local revisions have been done, two for Nearctic species (Gertsch 1934; Opell \& Beatty 1976) and one for New Zealand species (Forster 1970). Beside these revisions, Lehtinen (1967) published some comparative tables including diagnostic characters of 17 extant genera (10 currently valid, WSC 2020) and one more from Baltic amber. Presently, two genera, Cicurina and Hahnia C.L. Koch, 1841, have served as 'wastebin taxa' for new species descriptions, having a great morphological heterogeneity and accounting together for almost $70 \%$ of all the valid hahniid species (WSC 2020). The great heterogeneity and unclear delimitations in these and other hahniid genera are a recurrent note in new species publications (Forster 1970; Zhang et al. 2013; Huang et al. 2017).

The Hahniidae have a worldwide distribution, being more diverse in the Americas and Asia but also having a fair number of species described from Europe, Africa and Oceania (WSC 2020). In Asia, eight genera and 93 species have been recorded distributed from the Middle East to Eastern Russia and Japan. In South and Southeast Asia, hahniids have been reported from Hong Kong, Indonesia, Laos, Philippines, Southern China, Sri Lanka, Taiwan and Vietnam (Lehtinen 1967; Bosmans 1992; Barrion \& Litsinger 1995; Tang et al. 1996; Zhang et al. 2011, 2013; Zhang \& Zhang 2013; Liu et al. 2015; Huang et al. 2017). This is the first time the Hahniidae are reported from Thailand. Here we describe a new genus and two new species in this family based on molecular and morphological data. Additionally, we include a brief literature review on the rare six-eyed hahniids.

\section{Material and methods}

The hahniid species reported here were collected in the Chiang Mai Province, Thailand, between July $16^{\text {th }}$ and $28^{\text {th }} 2018$. All the specimens were captured using methods optimized for ground dwelling spiders: leaf litter sifting, Winkler extractors, pitfall traps and direct collecting on ground, among leaf litter and under rocks or logs.

Specimen habitus and other somatic characters were photographed under a Leica MI6SC stereo microscope equipped with a Nikon DS-Ri2 camera. Genitals were photographed using a Leica DM 2500 microscope attached to the same camera. Specimens were observed in ethanol using semi permanent slide preparations (Coddington 1983). Female genitalia were dissected, digested using pancreatine solution (Álvarez-Padilla \& Hormiga 2007) and cleared with methyl salicylate.

Four legs were taken from one individual of each species for DNA extraction. Six gene fragments (COI, H3, 12S, 16S, 18S and 28S) were amplified following M.A. Miller et al. (2010) and Wheeler et al. (2017) protocols; list of primers is provided in the Supplementary material (Supplementary file 1). Sequences were edited in Geneious Prime 2020.0.5. New sequences generated for this study were deposited in GenBank; accession numbers are reported in Table 1. All the specimens used here have been deposited in the collection of the Naturalis Biodiversity Center, Leiden, the Netherlands (RMNH. ARA.18411-RMNH.ARA.18415).

We used sequences from the three species we collected, as well as 15 other species with available sequences in GenBank. We used in total 14 species of Hahniidae, three species of Cybaeidae Banks, 1892, and one species of Agelenidae C.L. Koch, 1837, Agelena labyrinthica Walckenaer, 1805, as an outgroup. The sequences used to test the relationships and position of the new species within the Hahniidae are listed in Table 1. We used MAFFT ver. 7.450 online (https://mafft.cbrc.jp/alignment/server/) with default parameters to build the alignments. Alignments for $18 \mathrm{~S}$ were further trimmed manually due to the size difference of some sequences. $16 \mathrm{~S}$ and $12 \mathrm{~S}$ were not used due to the low availability of these loci for 
RIVERA-QUIROZ F.A. et al., New comb-tailed spiders (Araneae: Hahniidae) from Thailand

Table 1. GenBank accession numbers of DNA sequences used for our analyses. * marks the new sequences generated for the present work.

\begin{tabular}{|c|c|c|c|c|c|c|c|}
\hline Family & Species & COI & H3 & $12 \mathrm{~S}$ & $16 S$ & $18 \mathrm{~S}$ & $28 \mathrm{~S}$ \\
\hline Agelenidae & Agelena labyrinthica & FN554797 & KR074077 & & & AY633862 & AY633851 \\
\hline Cybaeidae & Calymmaria sp. 1 & DQ628611 & DQ628638 & & & DQ628702 & DQ628666 \\
\hline Cybaeidae & Cryphoeca exlineae & KM840792.1 & MN590107.1 & & & MN590054.1 & MN590084.1 \\
\hline Cybaeidae & Cybaeus morosus & FJ263792 & DQ628641 & & & DQ628707 & DQ628671 \\
\hline Hahniidae & Antistea brunnea & HQ580602.1 & MN590134.1 & & & MN590079.1 & MN590103.1 \\
\hline Hahniidae & Cybaeolus cf. rastellus & KY017745 & KY018252 & & & KY016481 & KY017117 \\
\hline Hahniidae & Cybaeolus pusillus & & KY018253.1 & & & KY016482.1 & KY017118.1 \\
\hline Hahniidae & Hahnia cinerea & GU683831.1 & MN590136.1 & & & MN590081.1 & MN590105.1 \\
\hline Hahniidae & Hahnia clathrata & FJ949005 & FJ949043 & & & FJ948923 & \\
\hline Hahniidae & Hahnia nava & KY270115 & KY018254.1 & & & KY016483.1 & \\
\hline Hahniidae & Hahnia ngai sp. nov. & MT433973* & MT445988* & & MT434973* & MT437224* & MT434975* \\
\hline Hahniidae & Hahnia ononidum & MG047916.1 & MN590137.1 & & & MN590082.1 & MN590106.1 \\
\hline Hahniidae & Hahnia saccata & MT433972* & & MT434903* & & MT437222* & \\
\hline Hahniidae & Hahnia sp. ZZ-2016 (China) & KR074066 & KR074092 & & & KR074014 & \\
\hline Hahniidae & Hahnia zhejiangensis & KR074067.1 & KR074093.1 & & & KR073991.1 & KR074041.1 \\
\hline Hahniidae & Hexamatia seekhaow sp. nov. & MT433971* & MT445987* & & MT434972* & MT437221* & MT434974* \\
\hline Hahniidae & Neoantistea agilis & HQ580773.1 & DQ628644.1 & & & DQ628714.1 & DQ628678.1 \\
\hline Hahniidae & Neoantistea quelpartensis & JN817206.1 & & & & JN816788.1 & JN816996.1 \\
\hline
\end{tabular}

the Hahniidae in GenBank; Table 1 only reports accession numbers of these markers for our sequences. Hahnia pusilla C.L. Koch, 1841, type species of Hahniidae, as well as two more species of Hahnia and two of Iberina Simon, 1881 had only COI sequences available in GenBank, therefore, they were not used in our final dataset. Matrix was built using COI, H3, 18S and 28S alignments in Sequence Matrix ver. 1.8 (http://www.ggvaidya.com/taxondna/); matrix is available in Supplementary file 2. Each locus was treated as a partition and examined with jModelTest2 (Darriba et al. 2012) in CIPRES (M.A. Miller et al. 2010) to get the best model fit for each; GTR $+\mathrm{I}+\mathrm{G}$ was selected in all the cases. Our datasets were analyzed using MEGA X (Kumar et al. 2018) for maximum parsimony (SPR, default values, bootstrap = 1000), RaXML (Stamatakis 2014) in CIPRES for maximum likelihood (GTR, bootstrap = 1000) and MrBayes ver. 3.2.6 (Ronquist \& Huelsenbeck 2003) for windows for the Bayesian inference $(\mathrm{GTR}+\mathrm{I}+\mathrm{G}$, two independent runs with one cold and three heated chains, mcmc $=1000000$ gen, samplefreq $=1000$, burnin $=2500)$. The program Tracer ver. 1.7.1 (Rambaut et al. 2018$)$ was used to analyze the performance of our BI analyses, and Mega X to estimate the genetic distances (JC model, gamma dist., gamma parameter $=1.00$; gaps data treatment $=$ pairwise deletion) for our whole dataset.

Abbreviations (in text and figures)

A $=$ epigynal atrium

$\mathrm{ALE}=$ anterior lateral eyes

ALS $=$ anterior lateral spinnerets

$\mathrm{AME}=$ anterior median eyes

$\mathrm{BI}=$ Bayesian inference

$\mathrm{Cd}=$ copulatory duct 


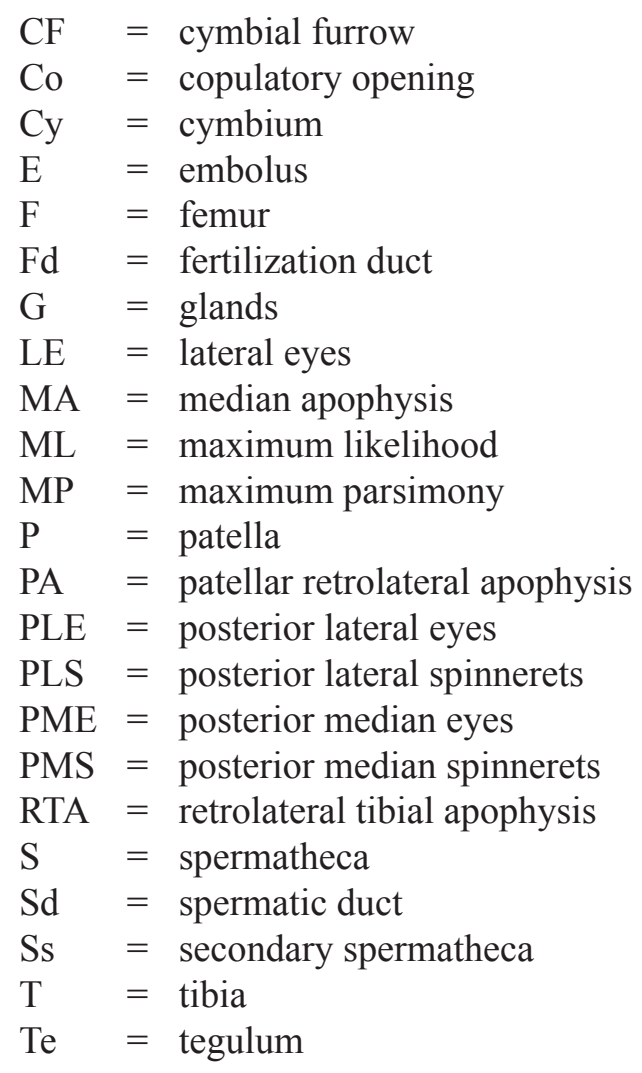

\section{Results}

\section{Phylogenetic analyses}

Topologies inferred by the three different phylogenetic analyses recovered nearly identical topologies (Fig. 1a-c). The genus Hahnia was homogeneously recovered as diphyletic. The clade Hahnia 1 was formed by six species of Hahnia, and Hahnia 2 by H. ngai sp. nov. and H. saccata, the two species of Hahnia we captured in Thailand. The clade Hahnia 1 showed high support, although the internal relationships are not fully resolved, having moderate to weak support values in the ML and MP analyses. This clade was found as a sister group to the new genus Hexamatia gen. nov. in all our trees. The clade Hahnia 2 appears to be more related to Antistea + Neoantistea. This branch is recovered and highly supported in all the analyses. The cluster formed by Antistea + Neoantistea is strongly supported although its internal relationships are not resolved and show weak to moderate support in the MP and ML. The three cybaeid representatives form a highly supported group that is consistently recovered as a sister to the monophyletic Hahniidae. Our BI showed an average deviation of split frequencies below 0.003 after 1000000 generations. None of the Estimated Sample size parameters fell below the commonly used threshold of 200 suggesting that our BI ran for an adequate length (Drummond et al. 2006; Lanfear et al. 2016). The trace plot and histograms of both runs are available in Supplementary files 3-4. Pairwise genetic distances for our alignment showed Hexamatia gen. nov. to have a wide range of distances with respect to species of Hahnia. When compared to species in Hahnia 1, this range went from 9.5 to $25 \%$ while the distance from Hahnia 2 was between 10.7 and 17.8\%. In comparison, the distances between Hexamatia gen. nov. and Antistea + Neoantistea were higher and less variable, between 18.0 and 19.2\%. See Supplementary file 5 for complete distance matrix. 
RIVERA-QUIROZ F.A. et al., New comb-tailed spiders (Araneae: Hahniidae) from Thailand

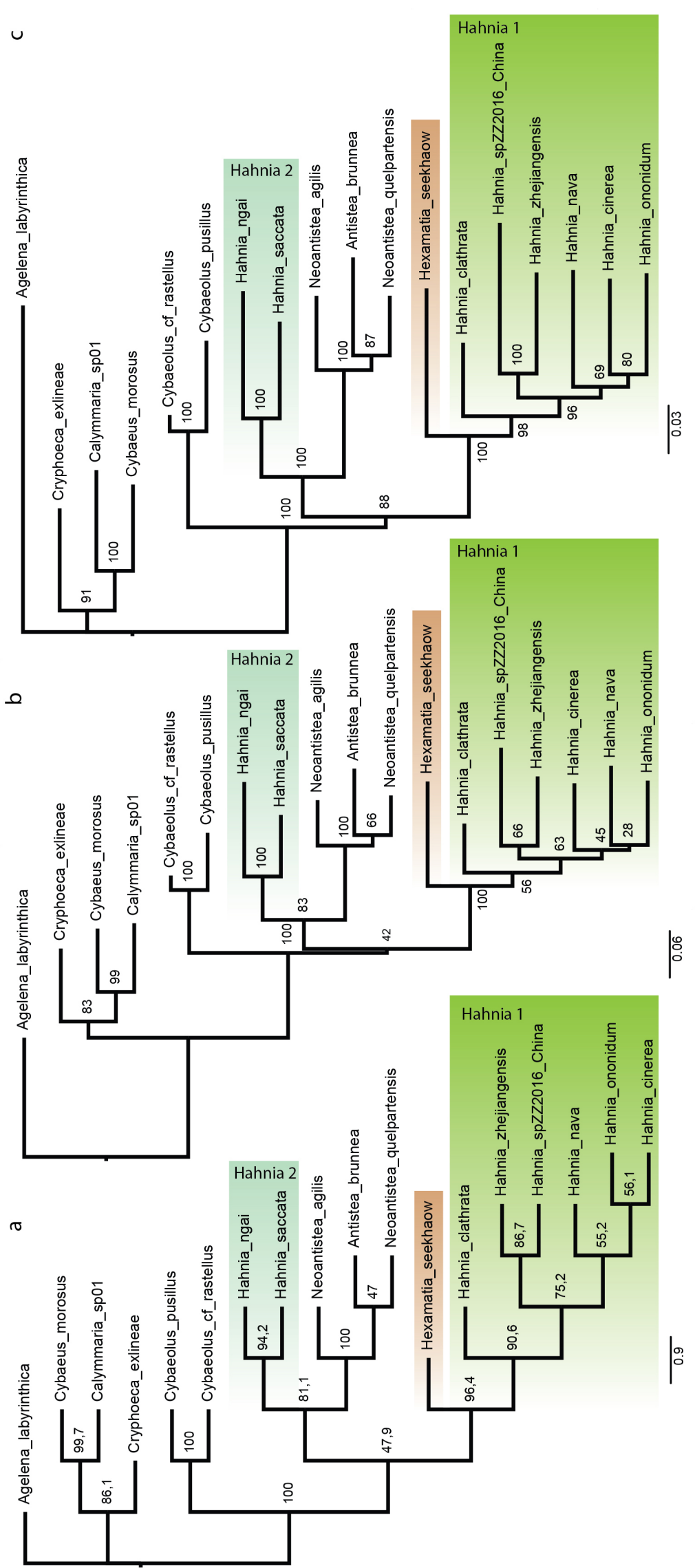

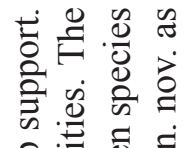

粉:

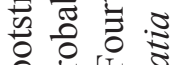

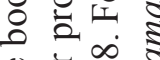

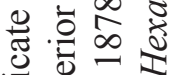

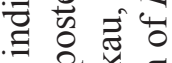

造总泀

记

品: :

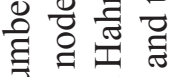

沿票

is

है

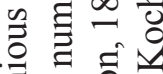

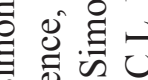

क्षे

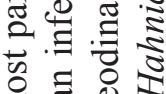

․ㅡ 원

के 0

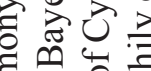

ن 记

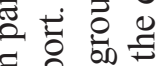

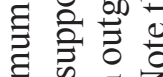

费 की

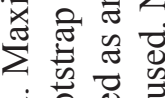

궁용

$\dot{0} 0$ व

空营芆

สี

$+\exists \infty$

屯

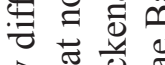

ลे क $\frac{0}{\pi}$

ชี

言寻芯U

음

पे

का

응 을 을

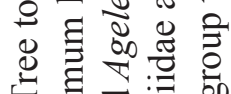

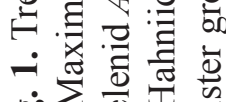

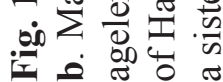




\title{
Taxonomy
}

\author{
Class Arachnida Lamarck, 1801 \\ Order Araneae Clerck, 1757 \\ Family Hahniidae Bertkau, 1878 \\ Genus Hexamatia gen. nov. \\ urn:1sid:zoobank.org:act:D9504970-17C3-43FF-9231-4D020BC176C7
}

\section{Type species}

Hexamatia seekhaow gen. et sp. nov.

\section{Diagnosis}

Hexamatia gen. nov. is distinguished from most hahniid genera by the combination of the following characters: presence of only six eyes, small body size close to $1 \mathrm{~mm}$, and body pale yellow to white, lacking abdominal patterns in males and having faint chevron lines in females (Zhang et al. 2011: fig. 23a-b). It can be separated from other six-eyed hahniids by the following combination of characters: from Amaloxenops Schiapelli \& Gerschman, 1958 by having a backward curved RTA without twists, and presence of PA on the pedipalp patella and MA on the bulb; from Intihuatana Lehtinen, 1967 by having an unbifurcated RTA, a shorter and bifurcated PA, and presence of MA; and from Scotospilus Zhang, Li \& Pham, 2013 by the comparatively short RTA, bifurcated PA and presence of MA.

\section{Etymology}

The genus name is formed from two Greek roots: hexa (six) and mati (eye). It refers to the number of eyes present in this genus, one of its diagnostic characters. The gender is feminine.

\section{Composition}

Hexamatia seekhaow gen. et sp. nov. and Hexamatia senaria (Zhang, Li \& Zheng, 2011) gen. nov., based on the original description and illustrations.

\section{Distribution}

Hexamatia seekhaow gen. et sp. nov. is known from Chiang Mai, Thailand; and Hexamatia senaria gen. nov. from Yunnan, China (Fig. 8).

Hexamatia seekhaow gen. et sp. nov. urn:lsid:zoobank.org:act:1D1D0DE7-8A2A-4469-8867-666F9AD6EAEB

Figs 2-3

\section{Diagnosis}

Hexamatia seekhaow gen. et sp. nov. greatly resembles $H$. senaria gen. nov. but can be distinguished by the bifurcated PA and having a slightly shorter RTA with a blunter tip (Figs 2f, 3d-e; Zhang et al. 2011: figs 21a-d, 22). Another putative difference is the presence of denticles in the distal portion of the RTA; these are not mentioned nor illustrated for $H$. senaria gen. nov.

\section{Etymology}

The species epithet is a derivation of the Thai seekhaow (white); refers to the lack of color on the body of the holotype of this species. 


\section{Type material}

\section{Holotype}

THAILAND - o'; Chiang Mai Province, Doi Suthep National Park; $18^{\circ} 48.502^{\prime}$ N, 98 $53.528^{\prime}$ E; $1409 \mathrm{~m}$ a.s.1.; 24-28 Jul. 2018; Booppa Petcharad, Jeremy Miller and F. Andrés Rivera-Quiroz leg.; montane evergreen forest with pine; hand coll. among leaf litter; RMNH.ARA.18411 (four legs used for DNA extraction).

\section{Description}

\section{Male holotype}

Carapace yellowish-white, pale brown in cephalic region (Fig. 2b-c). Legs same color as carapace. Abdomen white without chevron pattern, oval, longer than wide (Fig. 2a-c). Six eyes in two triads,
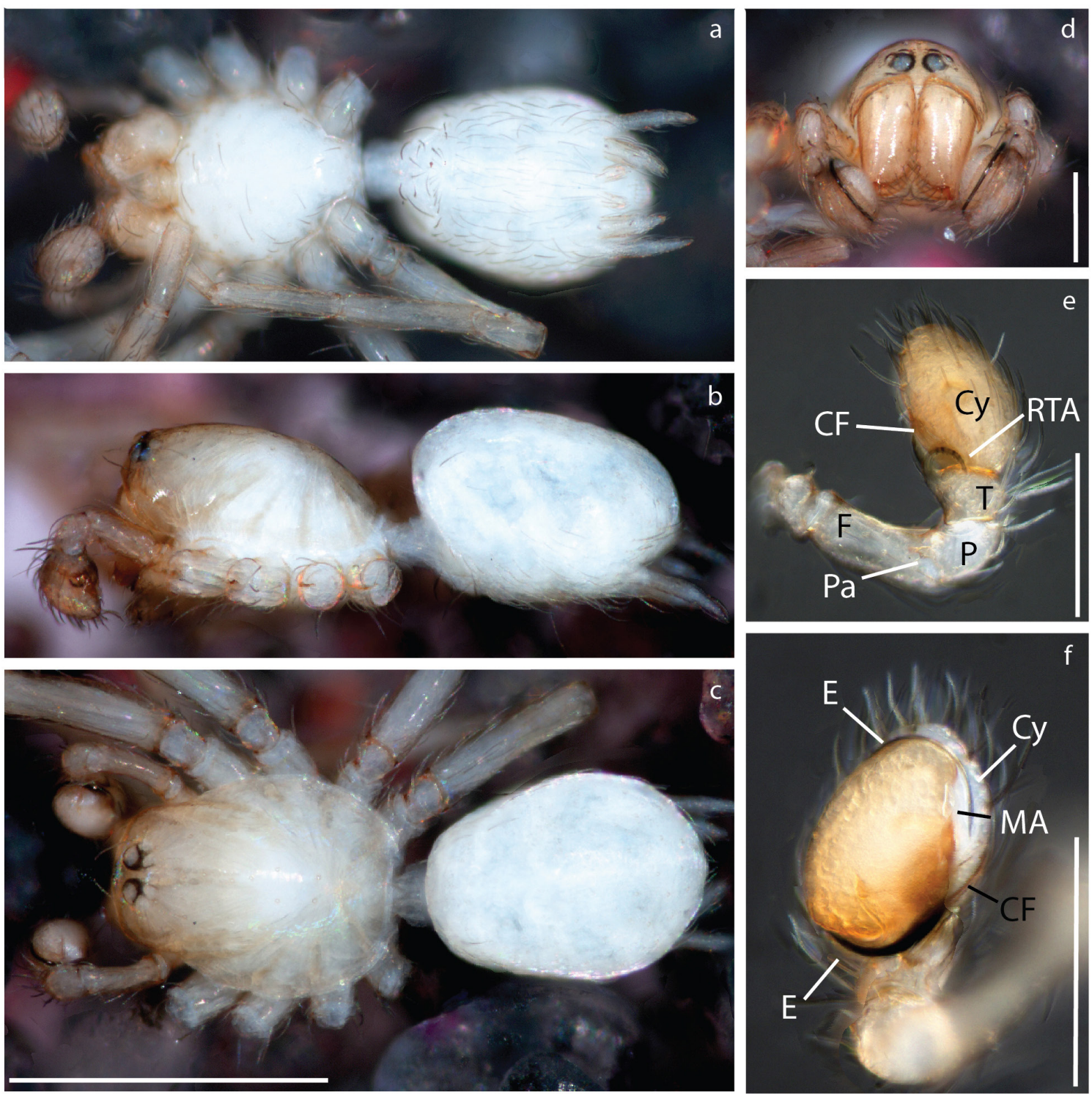

Fig. 2. Hexamatia seekhaow gen. et sp. nov., holotype, ${ }^{\lambda}$ (RMNH.ARA.18411). a-c. Habitus. a. Ventral view. b. Lateral view. c. Dorsal view. d. Prosoma, anterior view. e-f. Palp. e. Retrolateral view. f. Ventral view. Scale bars: $\mathrm{a}-\mathrm{c}=0.5 \mathrm{~mm} ; \mathrm{d}-\mathrm{f}=0.15 \mathrm{~mm}$. 

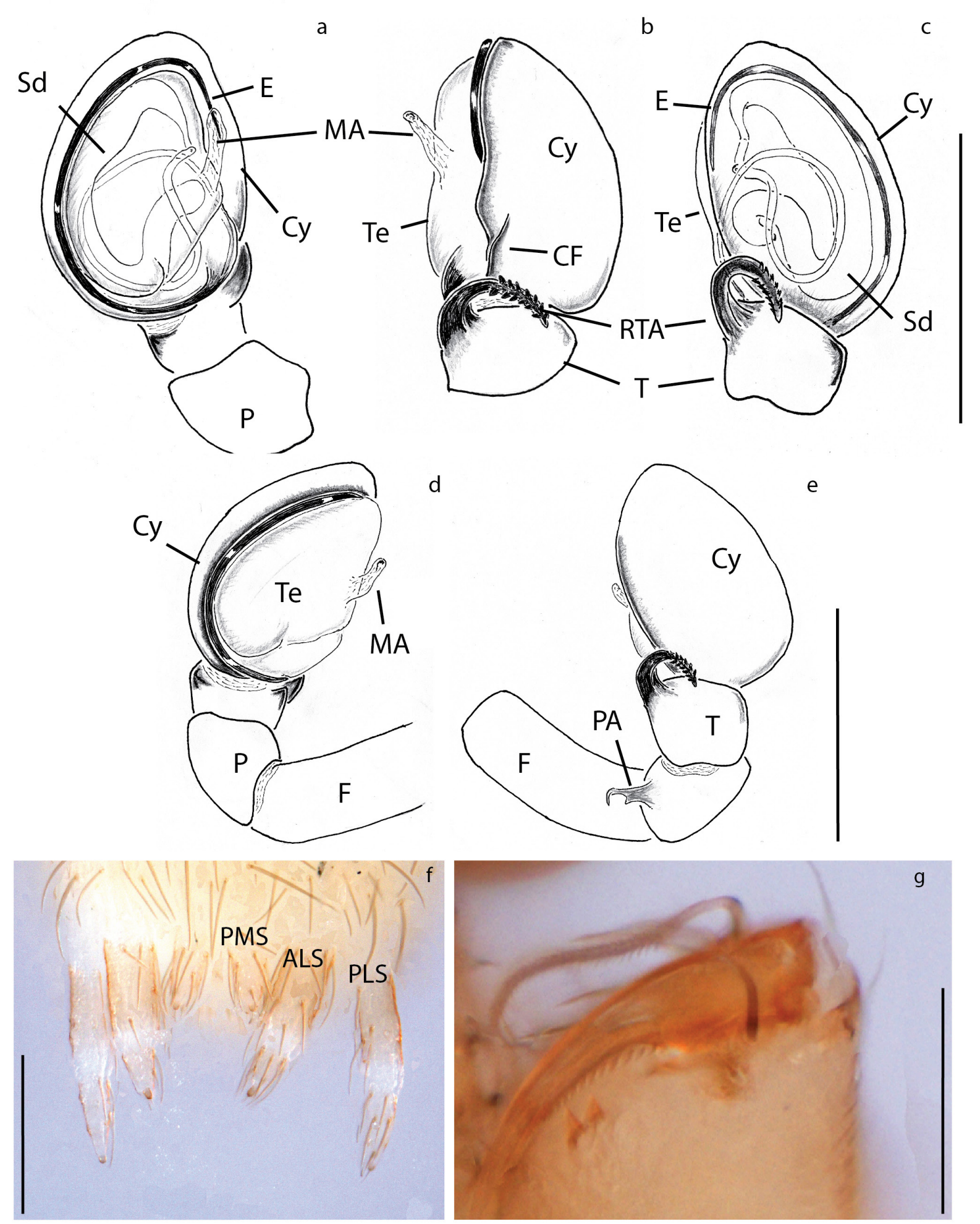

Fig. 3. Hexamatia seekhaow gen. et sp. nov., holotype, § (RMNH.ARA.18411). a-e. Palp. a. Ventral view, cleared. b. Retrolateral view. c. Dorso-retrolateral view, cleared. d. Prolateral view. e. Dorsoretrolateral view. f. Male spinnerets, ventral view. g. Chelicera. Posterior view. Scale bars: $\mathrm{a}-\mathrm{f}=$ $0.15 \mathrm{~mm} ; \mathrm{g}=0.5 \mathrm{~mm}$. 
AME absent ALE $0.04 \mathrm{~mm}$, PME $0.02 \mathrm{~mm}$, PLE $0.02 \mathrm{~mm}$, ALE-ALE $0.02 \mathrm{~mm}$, PME-PME $0.03 \mathrm{~mm}$, PME-PLE contiguous (Fig. 2d). Chelicerae with three promarginal and two retromarginal teeth (Fig. $3 \mathrm{~g}$ ). Tracheal spiracle near middle of abdomen (Fig. 2a).

PALP. Pale brown, same color as cephalic region (Fig. 2c). CF darker, almost as long as RTA (Figs 2e-f, $3 b$ ), oval-shaped from ventral view (Figs $2 \mathrm{f}, 3 \mathrm{a}$ ). Median apophysis narrow, elongate and transparent (Fig. 3a-b). Embolus filiform, black and long, originating retrollaterally and coiling clockwise around bulb (Figs 2f, 3a-b). RTA spur-like with dark rings. Patellar apophysis short and bifid, with the longer prong hook-shaped (Fig. 3c).

Measurements (in mm). Total length 1.1 , carapace 0.46 long, 0.33 wide; clypeus 0.01 ; chelicera 0.2 long, 0.1 wide; pedipalp 0.4 long; palp bulb 0.11 wide; leg I: femur 0.32 , patella 0.13 , tibia 0.26 , metatarsus 0.22 , tarsus 0.15 ; leg II: femur 0.31 , patella 0.12 , tibia 0.19 , metatarsus 0.19 , tarsus 0.15 ; leg III: femur 0.27 , patella 0.08 , tibia 0.16 , metatarsus 0.17 , tarsus 0.15 ; leg IV: femur 0.34 , patella 0.11 , tibia 0.22 , metatarsus 0.21 , tarsus 0.16 ; leg formula IV-I-II-III; abdomen 0.45 long, 0.34 wide.

\section{Distribution}

Known from the type locality, Doi Suthep National Park, Chiang Mai, Thailand (Fig. 8).

\section{Notes}

See the Discussion for remarks on six-eyed species.

Genus Hahnia C.L. Koch, 1841

Hahnia C.L. Koch, 1841: 61.

Type species

Hahnia pusilla C.L. Koch, 1841.

Hahnia ngai sp. nov. urn:1sid:zoobank.org:act:F9A7FE4B-77C4-4D9B-AFDB-A2FC6F5E0739

Figs $4,6 \mathrm{a}-\mathrm{c}$

\section{Diagnosis}

Hahnia ngai sp. nov. can be easily separated from other members of this genus by the simplified female genitalia. Copulatory ducts show only slightly swollen areas with glandular insertions (Figs 4g, 6b-c) but do not form a receptacle or secondary spermathecae (as seen in Figs 5g, 6e-f).

\section{Etymology}

The species epithet is a derivation of the Thai ngai (simple), in reference to the relatively simple vulva without the well-formed secondary spermathecae commonly seen in other species of Hahnia.

\section{Type material}

\section{Holotype}

THAILAND • क; Chiang Mai Province, Doi Suthep National Park; $18^{\circ} 48.502^{\prime}$ N, $98^{\circ} 53.528^{\prime}$ E; 1409 m a.s.1.; 24-28 Jul. 2018; Booppa Petcharad, Jeremy Miller and F. Andrés Rivera-Quiroz leg.; montane evergreen forest with pine; Winkler extractor; RMNH.ARA.18415 (four legs used for DNA extraction). 


\section{Paratypes}

THAILAND • 1 क ; Chiang Mai Province, Doi Inthanon National Park; $18^{\circ} 35.268^{\prime}$ N, 98 29.240' E; 2572 m a.s.1.; 24-28 Jul. 2018; Booppa Petcharad, Jeremy Miller and F. Andrés Rivera-Quiroz leg.; cloud forest; Winkler extractor; RMNH.ARA.18414 • 1 q; same collection data as for preceding; hand coll.; RMNH.ARA.18413.

\section{Description}

\section{Female}

Carapace pear-shaped, reddish-brown, slightly darker in cephalic region; texture smooth (Fig. 4c). AME $0.04 \mathrm{~mm}$, ALE $0.06 \mathrm{~mm}$, PME $0.07 \mathrm{~mm}$, PLE $0.04 \mathrm{~mm}$, AME-AME $0.03 \mathrm{~mm}$, AME-

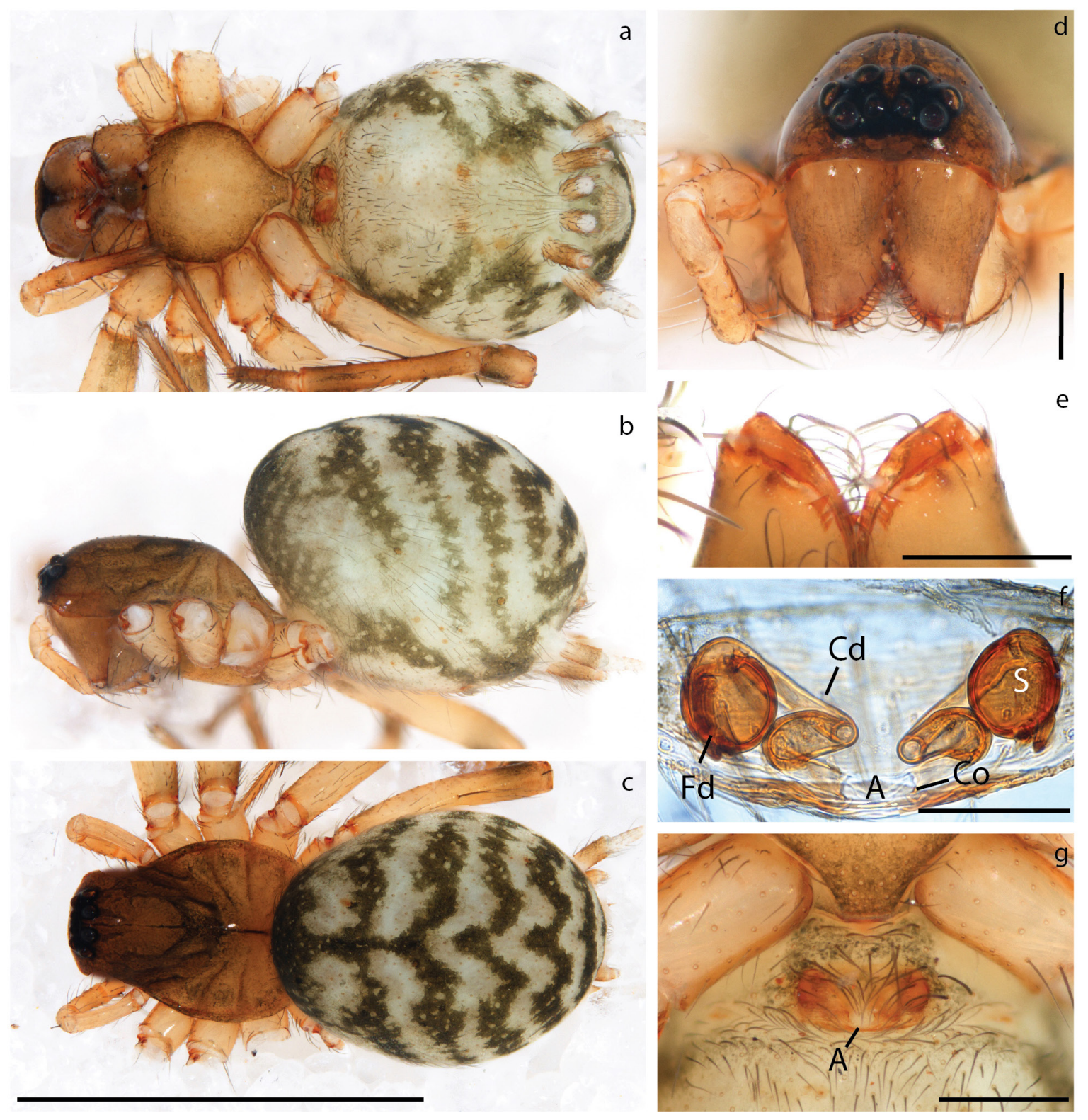

Fig. 4. Hahnia ngai sp. nov., holotype,, (RMNH.ARA.18415). a-c. Habitus. a. Ventral view. b. Lateral view. c. Dorsal view. d. Prosoma, anterior view. e. Chelicerae, posterior view. f-g. Epigynum. f. Dorsal view, cleared. g. Ventral view. Scale bars: $\mathrm{a}-\mathrm{c}=1.0 \mathrm{~mm}$; $\mathrm{d}-\mathrm{e}, \mathrm{g}=0.25 \mathrm{~mm} ; \mathrm{f}=0.1 \mathrm{~mm}$. 
ALE $0.02 \mathrm{~mm}$, PME-PME $0.05 \mathrm{~mm}$, PME-PLE $0.03 \mathrm{~mm}$ (Fig. 4d). Chelicerae with three promarginal and three retromarginal teeth (Fig. 4e). Legs pale brown, slightly darker on distal segments. Abdomen dark grey with light patches forming five to six chevron bands, oval, longer than wide (Fig. 4c). Tracheal spiracle near middle of abdomen (Fig. 4a).

Vulva. Epigynal plate semitransparent, spermathecae well visible due to transparency. Copulatory openings close together, forming small semi-circular atrium (Figs 4f-g, 6c). Spermatheca sub-spherical with brownish-red coloration (Fig. 4f). Copulatory ducts very simple, slightly swollen centrally (Figs 4f, $6 b-c)$.

Measurements (in mm). Total length 2.8, carapace 1.25 long, 0.91 wide; clypeus 0.09 ; chelicera 0.45 long, 0.25 wide; leg I: femur 0.95 , patella 0.37 , tibia 0.71 , metatarsus 0.72 , tarsus 0.55 ; leg II: femur 0.94, patella 0.34 , tibia 0.72 , metatarsus 0.68 , tarsus 0.55 ; leg III: femur 0.89 , patella 0.33 , tibia 0.63 , metatarsus 0.71 , tarsus 0.51 ; leg IV: femur 1.12 , patella 0.34 , tibia 0.93 , metatarsus 1.01 , tarsus 0.62 ; leg formula IV-I-II-III; abdomen 1.65 long, 1.23 wide.

\section{Distribution}

Known from two localities in Chiang Mai, Thailand (Fig. 8): Doi Suthep National Park (type locality), and the neighboring Doi Inthanon National Park.

Hahnia saccata Zhang, Li \& Zheng, 2011

Figs 5, 6d-f

Hahnia saccata Zhang, Li \& Zheng, 2011: 16, figs 14a-e, 15a-h, 16a-g.

\section{Material examined}

THAILAND • 2 q ${ }^{\circ}$; Chiang Mai Province, Doi Suthep National Park; $18^{\circ} 48.780^{\prime}$ N, 9855.928' E; 643 m a.s.l.; 25-28 Jul. 2018; Booppa Petcharad, Jeremy Miller and F. Andrés Rivera-Quiroz leg.; Dipterocarpus forest; hand coll.; RMNH.ARA.18412 (four legs of one specimen used for DNA extraction).

\section{Description}

\section{Female}

Carapace pear-shaped, reddish-brown, slightly darker in cephalic region; texture smooth (Fig. 5c). AME $0.06 \mathrm{~mm}$, ALE $0.11 \mathrm{~mm}$, PME $0.08 \mathrm{~mm}$, PLE $0.05 \mathrm{~mm}$, AME-AME $0.02 \mathrm{~mm}$, AMEALE $0.01 \mathrm{~mm}$, PME-PME $0.06 \mathrm{~mm}$, PME-PLE $0.04 \mathrm{~mm}$ (Fig. 5d). Chelicerae with three promarginal and seven retromarginal teeth (Fig. 5e). Legs same color as carapace, darker on proximal and distal part of each segment. Abdomen dark grey with light patches forming five to six chevron bands, oval, longer than wide (Fig. 5c). Tracheal spiracle near middle of abdomen (Fig. 5a).

VuLva. Epigynal plate dark. Copulatory openings close together but not forming an atrium (Figs $5 \mathrm{~g}$, 6f). Spermatheca sub-speherical with brown coloration (Fig. 5f). Copulatory ducts forming secondary spermatheca (Figs 5f, 6e-f).

MeAsurements (in mm). Total length 3.20, carapace 1.45 long, 1.04 wide; clypeus 0.10 ; chelicera 0.70 long, 0.33 wide; leg I: femur 1.22, patella 0.46 , tibia 1.13 , metatarsus 0.92 , tarsus 0.63 ; leg II: femur 1.12, patella 0.45 , tibia 0.90 , metatarsus 0.81 , tarsus 0.61 ; leg III: femur 0.98 , patella 0.41 , tibia 0.75 , metatarsus 0.80 , tarsus 0.49 ; leg IV: femur 1.31 , patella 0.45 , tibia 1.12 , metatarsus 1.03 , tarsus 0.65 ; leg formula IV-I-II-III; abdomen 1.73 long, 1.20 wide. 


\section{Distribution}

Known from the Menglun Nature Reserve, Yunnan, China (type locality), and Doi Suthep National Park, Chiang Mai, Thailand (present work) (Fig. 8).

\section{Discussion}

The Hahniidae, especially the Hahniinae, have traditionally been seen as an easily diagnosable group in part due to the transversal comb-shaped position of the spinnerets. Nevertheless, their position as a family has changed overtime, being initially considered a subfamily of the Agelenidae (Simon 1875;
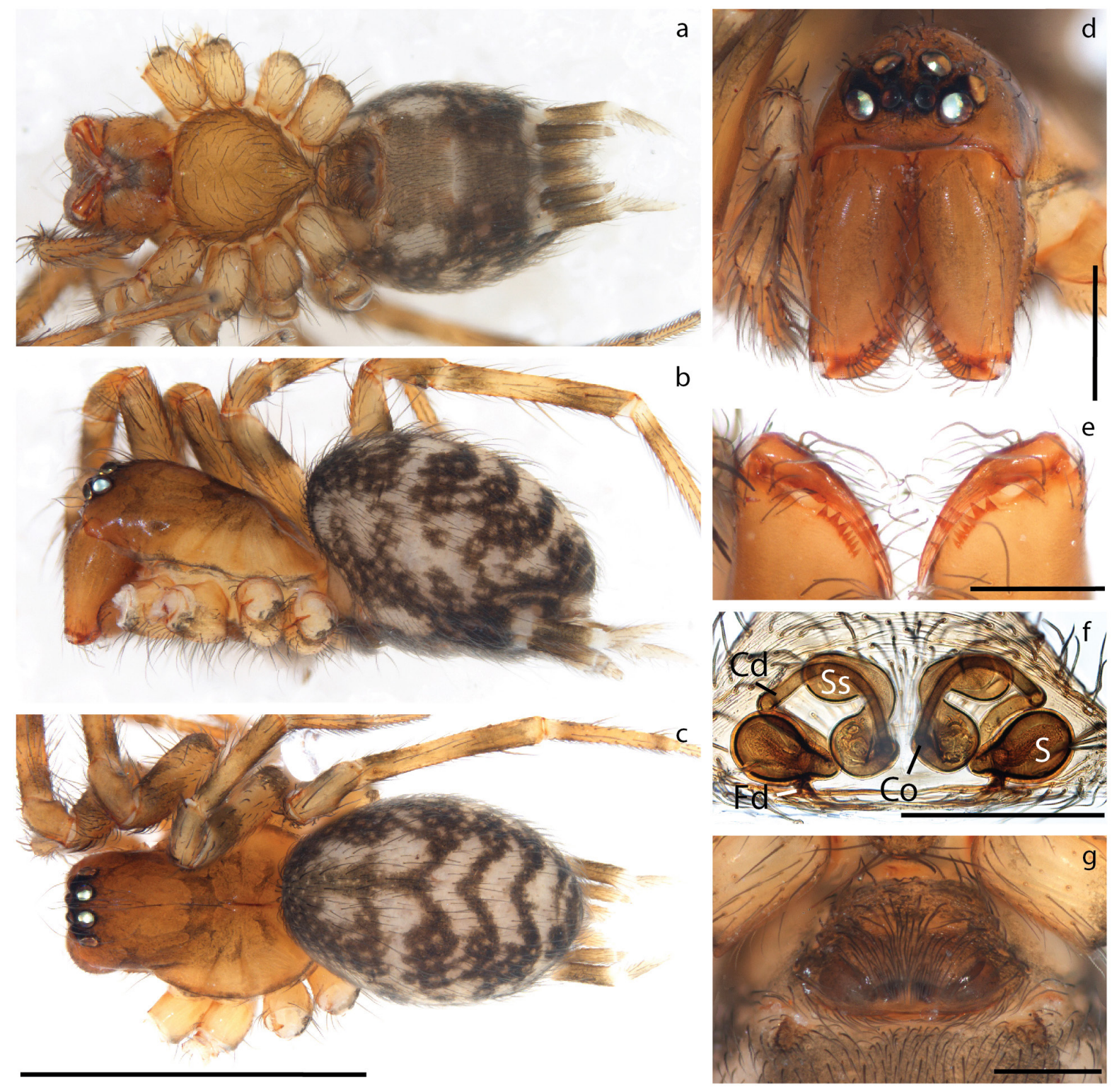

Fig. 5. Hahnia saccata Zhang, Li \& Zheng, 2011, $q$ (RMNH.ARA.18412). a-c. Habitus. a. Ventral view. b. Lateral view. c. Dorsal view. d. Prosoma, anterior view. e. Chelicerae, posterior view. $\mathbf{f}-\mathbf{g}$. Epigynum. f. Dorsal view, cleared. g. Ventral view. Scale bars: $a-c=1.0 \mathrm{~mm} ; \mathrm{d}=0.50 \mathrm{~mm}$; $-\mathrm{g}=0.25 \mathrm{~mm}$. 
Gertsch 1934; Lehtinen 1967, among others) and Dictynidae (Lehtinen 1967; Paquin \& Dupérré 2009; Wang et al. 2019, among others). Currently, the monophyly of the family is largely recognized, and its relations have been indirectly tested as a part of broad scoped phylogenetic studies (J.A. Miller et al. 2010; Wheeler et al. 2017). However, the relations between its genera have never been phylogenetically tested. Although our data did not include representatives of all the known hahniid genera, we found some consistent and well supported results with the 14 hahniid species and four loci we analyzed. The position of the new genus Hexamatia gen. nov. as a sister group to the core species of Hahnia in our study is confidently recovered in all our topologies. We consider that this plus the
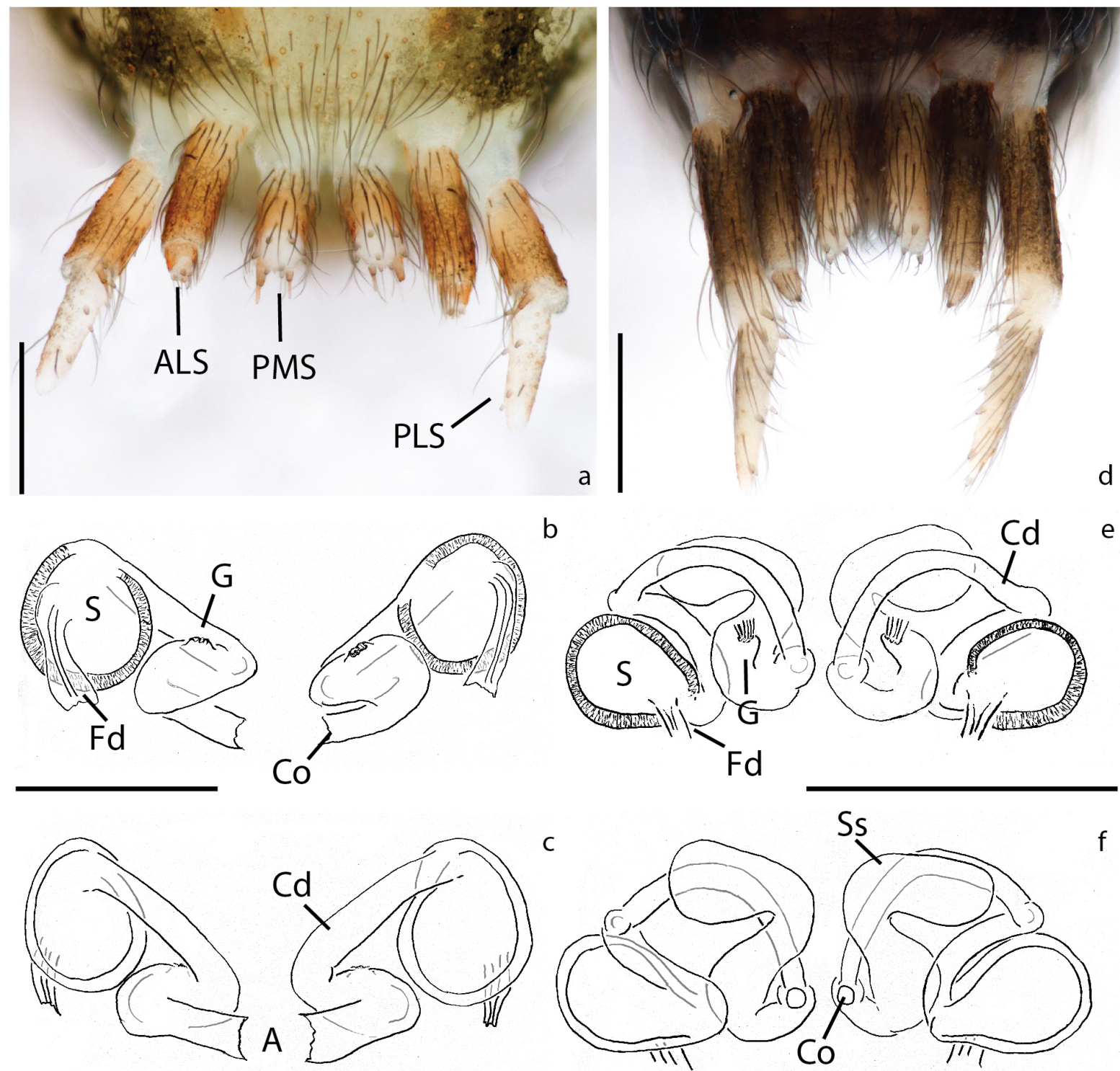

Fig. 6. Female spinnerets and genitals. a-c. Hahnia ngai sp. nov., holotype (RMNH.ARA.18415). a. Spinnerets, ventral view. b. Epigynum, cleared, dorsal view. c. Ventral view. d-f. Hahnia saccata Zhang, Li \& Zheng, 2011 (RMNH.ARA.18412). d. Spinnerets, ventral view. e. Epigynum, cleared, dorsal view. f. Ventral view. Scale bars: $\mathrm{a}, \mathrm{d}-\mathrm{f}=0.25 \mathrm{~mm}$; $\mathrm{b}-\mathrm{c}=0.1 \mathrm{~mm}$. 

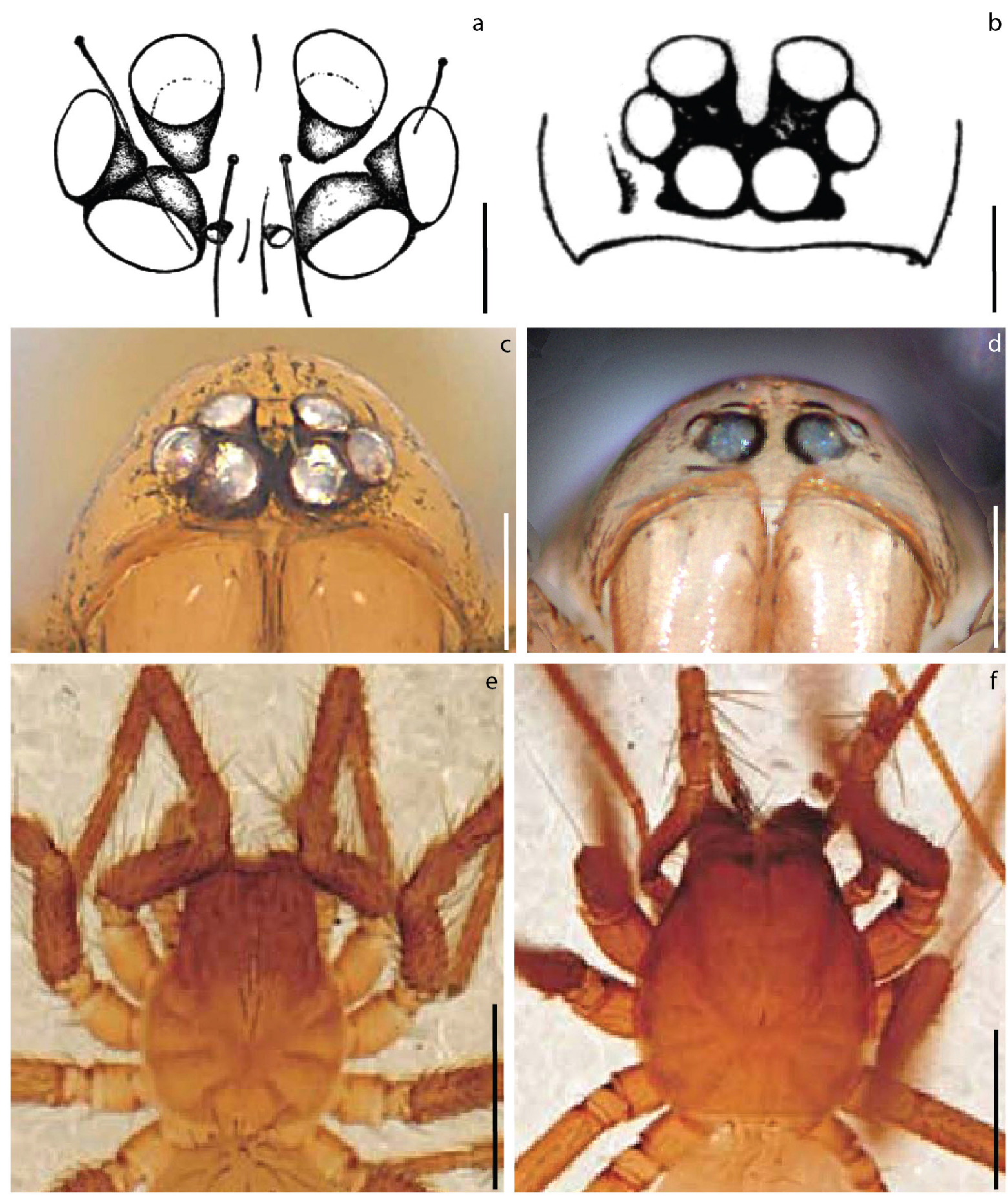

Fig. 7. Examples of eye reduction in the Hahniidae Bertkau, 1878. a. Eight eyes with minute AME, Alistra myops (Simon, 1898); modified from Schiapelli \& Gerschman de P. 1959. b-d. Six eyes. b. Amaloxenops vianai Schiapelli \& Gerschman, 1958; modified from Schiapelli \& Gerschman de P. 1958. c. Scotospilus longus Zhang, Li \& Pham, 2013; modified from Zhang et al. 2013. d. Hexamatia seekhaow gen. et sp. nov. e-f. No eyes, Iberina mazarredoi Simon, 1881; modified from FernándezPérez et al. 2014. Scale bars: $\mathrm{a}-\mathrm{d}=0.1 \mathrm{~mm}$; $\mathrm{e}-\mathrm{f}=0.5 \mathrm{~mm}$. 
morphological differences between the new genus and Hahnia (presence of six eyes, small size close to $1 \mathrm{~mm}$ and almost complete lack of coloration and abdominal patterns) are sufficient to consider it outside of the Hahnia 1 group, and as a genus of its own. We also propose a new combination for Hexamatia senaria gen. nov. Although we were not able to test the relationships between Hexamatia gen. nov. and other six-eyed hahniids like Amaloxenops (Lehtinen 1967; Schiapelli \& Gerschman de P. 1958), Intihuatana antarctica (Simon, 1902) (Dupérré \& Harms 2018) and Scotospilus (Zhang et al. 2013), clear morphological differences could be observed in somatic and genital characters like body size, coloration, size and shape of RTA and PA, and the presence of MA (see the diagnosis of Hexamatia gen. nov.).

The clade Hahnia 2 formed by H. saccata and H. ngai sp. nov. was found to be closely related to Antistea + Neoantistea in our analyses (Fig. 1a-c), suggesting that these species might be misplaced in Hahnia. However, these and many other Asian hahniids require a broader revision and more comprehensive phylogeny to fully resolve their relations within this family. Therefore, H. ngai sp. nov. and H. saccata remain in Hahnia; in the case of the later, as it was originally described by Zhang et al. (2011).

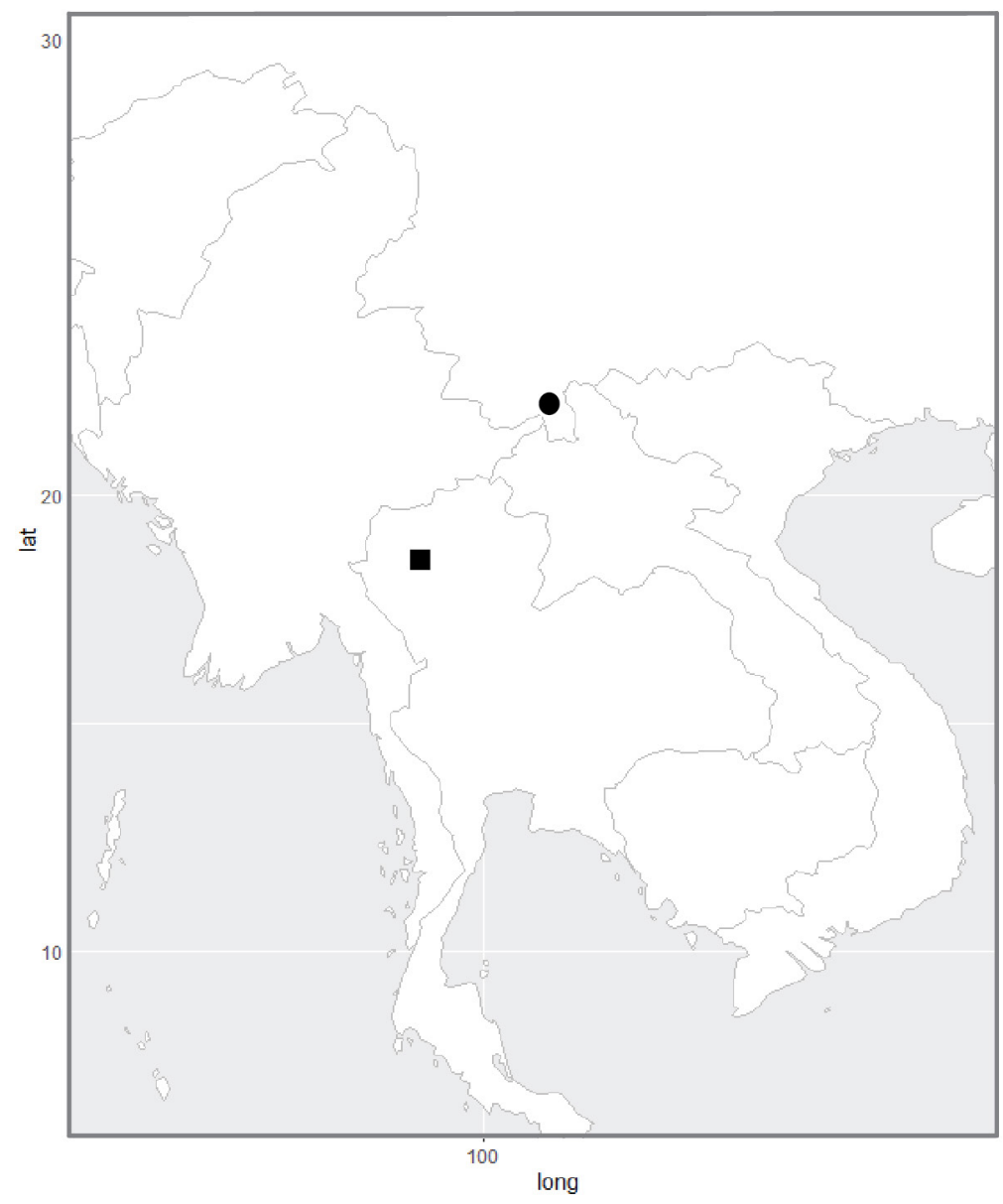

Fig. 8. Map of mainland Southeast Asia, showing the collecting sites of Zhang et al. (2011) (Hahnia saccata Zhang, Li \& Zheng, 2011 and Hexamatia senaria (Zhang, Li \& Zheng, 2011) gen. et comb. nov.), circle; and our new hahniid specimens (Hexamatia seekhaow gen. et sp. nov., Hahnia ngai sp. nov. and Hahnia saccata), square. 


\section{Eye reduction in the Hahniidae}

This phenomenon appears to be rare in hahniid spiders. Most known species of this family have eight eyes; still, some instances of eye reduction have been documented in at least six genera. The modifications of eyes range from size reduction of AME and lack of AME, to complete absence of eyes (Lehtinen 1967). The evolution of this phenomenon in this family has never been studied, and the relations of the species with reduced eyes are largely unknown. Even their taxonomy has been constantly a subject of debate (Lehtinen 1967; Schiapelli \& Gerschman de P. 1959; Catley 1999; Dupérré \& Harms 2018).

Size reduction of the AME (Fig. 7a) is relatively common being observed in several species of the following genera: Alistra Thorell, 1894 (Lehtinen 1967; Forster 1970; Ledoux 2004), Amaloxenops (Schiapelli \& Gerschman de P. 1959; Catley 1999; Dupérré \& Harms 2018), Hahnia (Lehtinen 1967; Ubick et al. 2005, among others) and Neohahnia Mello-Leitão, 1917 (Mello-Leitão 1917; Lehtinen 1967; Heimer \& Müller 1988). Reduction in number of eyes (Fig. 7b-d) is much rarer being documented only in a few species: Amaloxenops vianai Schiapelli \& Gerschman, 1958 (Schiapelli \& Gerschman de P. 1958; Lehtinen 1967), Hexamatia senaria gen. nov. (Zhang et al. 2011), Hexamatia seekhaow gen. et sp. nov., Intihuatana antarctica (Dupérré \& Harms 2018), Scotospilus longus Zhang, Li \& Pham, 2013 (Zhang et al. 2013), and two unpublished species documented in a revision of South American hahniids (Catley 1999); a quick examination of the illustrations and descriptions of these species suggest that they are not closely related. Finally, complete lack of eyes (Fig. 7e-f) has only been reported in the genus Iberina (Fernández-Pérez et al. 2014; Ledoux 2014). This wide range in the degree of eye reduction and broad geographical spread of this phenomenon suggest that eyes are a very plastic character and the loss or reduction might have evolved independently several times within this family. Nevertheless, a more comprehensive phylogeny of the Hahniidae is necessary to test this hypothesis.

\section{Acknowledgements}

Thanks to Joe Dulyapat and Choojai Petcharad for their great assistance and participation during our fieldwork in Thailand. Thanks to the editor Rudy Jocqué and two anonymous reviewers for their comments and suggestions. Funding for the first author was provided by CONACyT Becas al extranjero 294543/440613, Mexico. All specimens used in this study were collected under permit 5830802 emitted by the Department of National Parks, Wildlife and Plant Conservation, Thailand.

\section{References}

Álvarez-Padilla F. \& Hormiga G. 2007. A protocol for digesting internal soft tissues and mounting spiders for scanning electron microscopy. Journal of Arachnology 35 (3): 538-542. https://doi.org/10.1636/Sh06-55.1

Barrion A.T. \& Litsinger J.A. 1995. Family Hahniidae Bertkau (Hahniid spiders). In: Riceland Spiders of South and Southeast Asia: 338-342. CAB International, Wallingford.

Bosmans R. 1992. Spiders of the family Hahniidae from Sulawesi, Indonesia with remarks on synonymy and zoogeography (Arachnida: Araneae: Hahniidae). Belgian Journal of Zoology 122 (1): 83-91.

Catley K.M. 1999. The Systematics of the Hahniid Spiders of Austral South America (Araneae, Hahniidae). PhD thesis, Cornell University, USA.

Coddington J.A. 1983. A temporary slide-mount allowing precise manipulation of small structures. Verhandlungen des Naturwissenschaftlichen Vereins in Hamburg 26: 291-292.

Darriba D., Taboada G.L., Doallo R. \& Posada D. 2012. JModelTest 2: more models, new heuristics and parallel computing. Nature Methods 9: 772. https://doi.org/10.1038/nmeth.2109 
RIVERA-QUIROZ F.A. et al., New comb-tailed spiders (Araneae: Hahniidae) from Thailand

Drummond A.J., Ho S.Y.W., Phillips M.J. \& Rambaut A. 2006. Relaxed phylogenetics and dating with confidence. PLoS Biology 4 (5): e88. https://doi.org/10.1371/journal.pbio.0040088

Dupérré N. \& Harms D. 2018. Raising the dead: rediscovery and redescription of some lost spider types (Araneae) described by Eugène Simon. Evolutionary Systematics 2: 1-20.

https://doi.org/10.3897/evolsyst.2.24122

Fernández-Pérez J., Castro A. \& Prieto C.E. 2014. Arañas cavernícolas (Araneae) de la región vascocantábrica: nuevos registros y actualización del conocimiento. Revista Ibérica de Aracnología 25: 7791.

Forster R.R. 1970. The spiders of New Zealand. Part III. Desidae, Dictynidae, Hahniidae, Amaurobioididae, Nicodamidae. Otago Museum Bulletin 3: 1-184.

Gertsch W.J. 1934. Some American spiders of the family Hahniidae. American Museum Novitates 712: 1-32. Available from http://digitallibrary.amnh.org/handle/2246/4178 [accessed 26 Oct. 2020].

Heimer S. \& Müller H.G. 1988. Spiders from Colombia VIII. Neohahnia chibcha n. sp. from the Sierra Nevada mountains, northern Colombia (Arachnida, Araneida, Hahniidae). Bulletin of the British Arachnological Society 7: 229-230.

Huang G.Q., Zhang Z.S. \& Liu Y.H. 2017. Review of the comb-tailed spider genus Hahnia C.L. Koch 1841 (Hahniidae) from Gaoligong mountains in Yunnan, China. Zootaxa 4344 (3): 444-464.

https://doi.org/10.11646/zootaxa.4344.3.2

Koch C.L. 1841. Die Arachniden. Getreu nach der Natur abgebildet und beschrieben. Achter Band. C.H. Zeh'schen Buchhandlung, Nuremberg. https://doi.org/10.5962/bhl.title.43744

Kumar S., Stecher G., Li M., Knyaz C. \& Tamura K. 2018. MEGA X: Molecular Evolutionary Genetics Analysis across computing platforms. Molecular Biology and Evolution 35 (6): 1547-1549.

https://doi.org/10.1093/molbev/msy096

Lanfear R., Hua X. \& Warren D.L. 2016. Estimating the effective sample size of tree topologies from Bayesian phylogenetic analyses. Genome Biology and Evolution 8 (8): 2319-2332.

https://doi.org/10.1093/gbe/evw171

Ledoux J.C. 2004. Araignées de l'île de La Réunion: I. Hahniidae, Ctenidae, Thomisidae et Clubionidae (Araneae). Revue Arachnologique 14 (11): 159-191.

Ledoux J.C. 2014. Les Hahniidae de la faune française. Revue Arachnologique 2 (1): 29-40.

Lehtinen P.T. 1967. Classification of the cribellate spiders and some allied families, with notes on the evolution of the suborder Araneomorpha. Annales Zoologici Fennici 4: 199-467.

Liu N., Huang G.Q. \& Zhang Z.S. 2015. A new species of the genus Hahnia (Araneae: Hahniidae) from South China. Zootaxa 3994 (2): 295-300. https://doi.org/10.11646/zootaxa.3994.2.10

Mello-Leitão C.F. 1917. Generos e especies novas de Araneidos. Archivos da Escola Superior de Agricultura e Medicina Veterinaria, Rio de Janeiro 1: 3-19.

Miller J.A., Griswold C.E. \& Haddad C.R. 2010. Taxonomic revision of the spider family Penestomidae (Araneae, Entelegynae). Zootaxa 2534 (1): 1-36. https://doi.org/10.11646/zootaxa.2534.1.1

Miller M.A, Pfeiffer W. \& Schwartz T. 2010. Creating the CIPRES Science Gateway for inference of large phylogenetic trees. In: 2010 Gateway Computing Environments Workshop, GCE 2010: 1-8. https://doi.org/10.1109/GCE.2010.5676129

Opell B.D. \& Beatty J.A. 1976. The Nearctic Hahniidae (Arachnida: Araneae). Bulletin of the Museum of Comparative Zoology 147 (9): 393-433. 
Paquin P. \& Dupérré N. 2009. A first step towards the revision of Cicurina: redescription of type specimens of 60 troglobitic species of the subgenus Cicurella (Araneae: Dictynidae), and a first visual assessment of their distribution. Zootaxa 2002 (1): 1-67. https://doi.org/10.11646/zootaxa.2002.1.1

Rambaut A., Drummond A.J., Xie D., Baele G. \& Suchard M.A. 2018. Posterior summarization in Bayesian phylogenetics using Tracer 1.7. Systematic Biology 67 (5): 901-904.

https://doi.org/10.1093/sysbio/syy032

Ronquist F. \& Huelsenbeck J.P. 2003. MrBayes 3: Bayesian phylogenetic inference under mixed models. Bioinformatics 19 (12): 1572-1574. https://doi.org/10.1093/bioinformatics/btg180

Roth V.D. 1967. A review of the South American spiders of the family Agelenidae (Arachnida, Araneae). Bulletin of the American Museum of Natural History 134: 297-346. Available from http://digitallibrary.amnh.org/handle/2246/1984 [accessed 26 Oct. 2020].

Schiapelli R.D. \& Gerschman de P. B.S. 1958. Arañas argentinas III. Arañas de Misiones. Revista del Museo Argentino de Ciencias Naturales Bernardino Rivadavia 3: 187-231.

Schiapelli R.D. \& Gerschman de P. B.S. 1959. Aclaración sobre los caracteres genéricos del género Bigois Simon, 1898 (Araneae, Hahniidae). Revista de la Sociedad Entomológica Argentina 21: 129132. Available from https://www.biotaxa.org/RSEA/article/view/48043 [accessed 26 Oct. 2020].

Simon E. 1875. Les Arachnides de France. Vol. 2. Librarie Encyclopédique de Roret, Paris.

Stamatakis A. 2014. RAxML version 8: a tool for phylogenetic analysis and post-analysis of large phylogenies. Bioinformatics 30 (9): 1312-1313. https://doi.org/10.1093/bioinformatics/btu033

Tang Y.Q., Yang Y.T. \& Kim J.P. 1996. A new species of genus Hahnia (Araneae: Hahniidae) from China. Korean Arachnology 12 (2): 67-69.

Ubick D., Paquin P., Cushing P.E. \& Roth V. 2005. Spiders of North America: An Identification Manual. $2^{\text {nd }}$ Ed. American Arachnological Society.

Wang L.Y., Zhou G.C. \& Peng X.J. 2019. Four new species of the spider genus Cicurina Menge, 1871 from China (Araneae: Dictynidae). Zootaxa 4615 (2): 351-364. https://doi.org/10.11646/zootaxa.4615.2.7

Wheeler W.C., Coddington J.A., Crowley L.M., Dimitrov D., Goloboff P.A., Griswold C.E., Hormiga G., Prendini L., Ramírez M.J., Sierwald P., Almeida-Silva L., Álvarez-Padilla F., Arnedo M.A., Benavides Silva L.R., Benjamin S.P., Bond J.E., Grismado C.J., Hasan E., Hedin M., Izquierdo M.A., Labarque F.M., Ledford J., Lopardo L., Maddison W.P., Miller J.A., Piacentini L.N., Platnick N.I., Polotow D., SilvaDávila D., Scharff N., Szüts T., Ubick D., Vink C.J., Wood H.M. \& Zhang J. 2017. The spider tree of life: phylogeny of Araneae based on target-gene analyses from an extensive taxon sampling. Cladistics 33: 574-616. https://doi.org/10.1111/cla.12182

WSC. 2020. World Spider Catalog, ver. 21.0. Natural History Museum Bern. https://doi.org/10.24436/2

Zhang Z.S. \& Zhang Y.G. 2013. Synonymy and misidentification of three Hahnia species (Araneae: Hahniidae) from China. Zootaxa 3682 (4): 521-533. https://doi.org/10.11646/zootaxa.3682.4.3

Zhang Z.S., Li S. \& Zheng G. 2011. Comb-tailed spiders from Xishuangbanna, Yunnan Province, China (Araneae, Hahniidae). Zootaxa 2912 (1): 1-27. https://doi.org/10.11646/zootaxa.2912.1.1

Zhang Z.S., Li S. \& Pham D.S. 2013. First description of comb-tailed spiders (Araneae: Hahniidae) from Vietnam. Zootaxa 3613 (4): 343-356. https://doi.org/10.11646/zootaxa.3613.4.2 
Published on: 20 November 2020

Topic editor: Rudy Jocqué

Desk editor: Pepe Fernández

Printed versions of all papers are also deposited in the libraries of the institutes that are members of the EJT consortium: Muséum national d'histoire naturelle, Paris, France; Meise Botanic Garden, Belgium; Royal Museum for Central Africa, Tervuren, Belgium; Royal Belgian Institute of Natural Sciences, Brussels, Belgium; Natural History Museum of Denmark, Copenhagen, Denmark; Naturalis Biodiversity Center, Leiden, the Netherlands; Museo Nacional de Ciencias Naturales-CSIC, Madrid, Spain; Real Jardín Botánico de Madrid CSIC, Spain; Zoological Research Museum Alexander Koenig, Bonn, Germany; National Museum, Prague, Czech Republic.

\section{Supplementary material}

Supplementary file 1. List of primers used in this study. https://doi.org/10.5852/ejt.2020.724.1157.3141

Supplementary file 2. Aligned matrix in nexus format. https://doi.org/10.5852/ejt.2020.724.1157.3143

Supplementary file 3. Results of the BI analysis shown in a trace plot using the program Tracer ver. 1.7.1 (Rambaut et al. 2018). https://doi.org/10.5852/ejt.2020.724.1157.3145

Supplementary file 4. Results of the BI analysis shown in a histogram using the program Tracer ver. 1.7.1 (Rambaut et al. 2018). https://doi.org/10.5852/ejt.2020.724.1157.3147

Supplementary file 5. Pairwise genetic distance for our data set obtained using MEGA X (Kumar et al. 2018). https://doi.org/10.5852/ejt.2020.724.1157.3149 